\title{
Assess the Possibility of Screening and Supervising Influenza A (H7N9) Virus-Infected Patients via Rapid Point-of-Care-Test Kit with Upper or Lower Respiratory Specimens
}

Zhengtu Li ${ }^{1 \#}$, Li Li ${ }^{2 \#}$, Shiguan $\mathbf{W u}^{1}$, Xiaobo $\mathrm{Li}^{3}$, Runfeng $\mathrm{Li}^{1}$, Wenbo Huang ${ }^{1}$, Sihua Pan ${ }^{1}$, Wenda Guan ${ }^{1}$, Jicheng Huang ${ }^{3^{*}}$ and Zifeng Yang ${ }^{1,4^{*}}$

${ }^{1}$ State Key Laboratory of Respiratory Diseases, Guangzhou Institute of Respiratory Disease, National Clinical Centre of Respiratory Disease, The First Affiliated Hospital, Guangzhou Medical University, Guangzhou, China

${ }^{2}$ The First Hospital of Yulin, Yulin, China

${ }^{3}$ Guangdong Entry-exit Inspection and Quarantine Bureau Technology Center, Guangzhou, China

${ }^{4}$ Chinese Medical Faculty, Macau University of Science and Technology, Macau, China

\#These authors contributed equally to this work

\begin{abstract}
The purpose of this study was to assess the possibility of screening and supervising influenza A (H7N9) virusinfected patients via rapid point-of-care-test kit with upper or lower respiratory specimens. Here, we demonstrate that the POCT kits can detect H7N9 virus (Guangzhou strain) in different type of samples, which obtained from upper and lower respiratory tract, via the simulated experiment. The detection limit ranged from 4 to $6 \log _{10} \mathrm{TCID}_{50} / \mathrm{mL}$ and $2.78 \times$ 107 to $1.05 \times 108$ copies/mL in PBS and nasopharyngeal swab solution (NSS) solutions respectively. Furthermore, the detection ranges were enhanced by 0.5 or $1 \log _{10} \mathrm{TCID}_{50} / \mathrm{mL}$ in BALF or sputum solution (SS) diluents for some parts of the POCT kits. Furthermore, we observed that there were higher replication and longer screening of H7N9 virus in lower respiratory tract (LRT) samples, such as endotracheal aspirate (ETA) and sputum, from the H7N9 virus-infected patients, although the detection results of POCT kits were negative for these clinical samples. So that, we think that POCT kits can be used to screen and supervise H7N9 virus-infected patients if in the accurate timing. And the LRT samples, special ETA and sputum, seem a good sample option for detecting H7N9 virus via POCT kits, so we need pay more attention to the LRT samples when the new POCT kits were developed.
\end{abstract}

Keywords: H7N9 virus; Point-of-care test kit; Clinical sample; Sputum

\section{Introduction}

A new influenza virus, which is of avian origin and called avian influenza A (H7N9) virus, emerged around the Yangtze River delta in March 2013 in China, and caused serious human disease and death $[1,2]$. Then the infection spread to South China and the second wave of the epidemic occurred in Guangdong province of South China in the winter of 2013 [3]. Additionally, data from China's National Surveillance System for Pneumonia of Unknown Etiology showed that infection with H7N9 could also result in mild or asymptomatic cases $[2,4]$ in humans. The reality is hypothesized to be much worse because of a number of unrecognized infections [2]. Therefore, a quick and accurate diagnosis is essential, especially for mild or asymptomatic cases.

Point-of-care test (POCT) kits are based on antibodies that specifically bind to the influenza virus nucleoprotein, and they can provide results within 15-30 min. Thus, they are used on an outpatient basis to screen and supervise for influenza virus infection. As reported previously, commercially available POCT kits could be used to detect the H7N9 virus [5-7]. Therefore, we hypothesise that POCT kits can be sued to screen and supervise H7N9 patients as seasonal influenza using the upper or lower respiratory specimens.

Six commercially available POCT kits were used in this study, which are commonly used in China and other countries and all kits within the effective using. Including $\operatorname{Vondfo}(\mathrm{A}+\mathrm{B})$ and $\operatorname{Vondfo}(\mathrm{H} 7)$ (Wondfo, Biotech Company, China), QuickNavi (Denka Seiken, Japan), ImunoAce (TAUNS, Japan), BD Directigen (Becton, Dickinson and company, Sparks, USA) and Alere BinaxNOW (Alere, Unites States). The using virus strains, influenza A (H7N9) virus A/ Guangzhou/8/2013 (Guangdong province), which was provided by the Chinese National Influenza Center, and the influenza A (H1N1) pdm09 virus A/Guangzhou/GIRD02/09 [8] (which was stored in the State Key Laboratory of Respiratory Diseases, Guangzhou, China). Additionally, for assessing whether the POCT kits can test the H7N9 virus in different upper and lower respiratory specimens or not, the nasopharyngeal swab, sputum and bronchoalveolar lavage fluid (BALF) were obtained from healthy person and confirmed to be free of the influenza virus, with which to make the different solutions: BALF (mainly $0.9 \%$ saline), sputum solution (SS), which contains $0.3 \%$ DL-dithiothreitol(DTT), and nasopharyngeal swab solution (NSS), which mainly contains minimum essential medium (MEM) to make the basal simulated experiment. Viruses were standardized to $1 \times 10^{7} \mathrm{TCID}_{50} / \mathrm{mL}$, and serial half- $\log _{10}$ dilutions were made in PBS, BALF, SS, and NSS solution. Furthermore, the realistic respiratory samples of $\mathrm{H} 7 \mathrm{~N} 9$ virus-infected patients were collected between August 2013 and January 2015, throughout the period of hospitalization in the First Affiliated Hospital of Guangzhou Medical University in Guangdong province within the second wave of epidemic. The samples from different respiratory tract at different point-in-time included upper respiratory specimen (URS), such as nasopharyngeal swab (NS), throat swab (TS), and nasopharyngeal secretion (NPS); lower respiratory specimen (LRS), such as endotracheal aspirate

${ }^{*}$ Corresponding authors: Zifeng Yang, State Key Laboratory of Respiratory Diseases, Guangzhou Institute of Respiratory Disease, National Clinical Centre of Respiratory Disease, The First Affiliated Hospital, Guangzhou Medical University, Guangzhou, China, Tel: + 8538897 2326; E-mail: jeffyah@163.com

Jicheng Huang, Guangdong Entry-exit Inspection and Quarantine Bureau Technology Center, Guangzhou, China, E-mail: huangjc@yahoo.cn

Received September 14, 2016; Accepted October 03, 2016; Published October 07, 2016

Citation: Li Z, Li L, Wu S, Li X, Li R, et al. (2016) Assess the Possibility of Screening and Supervising Influenza A (H7N9) Virus-Infected Patients via Rapid Point-of-Care-Test Kit with Upper or Lower Respiratory Specimens. J Pulm Respir Med 6: 371. doi: 10.4172/2161-105X.1000371

Copyright: ( $2016 \mathrm{Li} \mathrm{Z}$, et al. This is an open-access article distributed under the terms of the Creative Commons Attribution License, which permits unrestricted use, distribution, and reproduction in any medium, provided the original author and source are credited. 
Citation: Li Z, Li L, Wu S, Li X, Li R, et al. (2016) Assess the Possibility of Screening and Supervising Influenza A (H7N9) Virus-Infected Patients via Rapid Point-of-Care-Test Kit with Upper or Lower Respiratory Specimens. J Pulm Respir Med 6: 371. doi: 10.4172/2161-105X.1000371

Page 2 of 3

(ETA), sputum and bronchoalveolar lavage fluid (BALF). NS, TS and NPS mainly contain MEM, sputum and ETA were handled by DTT, and BALF was mainly $0.9 \%$ saline. The ethical approval of the study protocol was granted from the Ethics Committee of the First Affiliated Hospital of Guangzhou Medical University [8]. The virus detection was according to the manufacturer's instructions with POCT kits [9] and real-time PCR kit (Liferiver, Shanghai, China, RR-0309-02) [10]. The experiment was performed in the Guangdong Entry-exit Inspection and Quarantine Bureau Technology Center (BSL-3 lab).

Our results showed that in the basal simulated experiment, based on $\log _{10} \mathrm{TCID}_{50} / \mathrm{mL}$, NSS had the same detection limit as PBS. However, in BALF, the detection limits of the QuickNavi, ImunoAce, and Alere BinaxNOW kits were enhanced by $0.5 \log _{10} \mathrm{TCID}_{50} / \mathrm{mL}$, and the detection limits of the Wondfo $(\mathrm{A}+\mathrm{B})$, Wondfo $(\mathrm{H} 7)$, and BD Directigen kits were unchanged. Additionally, in SS, the detection limits of the Wondfo (H7), ImunoAce, and BD Directigen kits were increased by 0.5 or $1 \log _{10} \mathrm{TCID}_{50} / \mathrm{mL}$, while the detection limits of the Wondfo $(\mathrm{A}+\mathrm{B})$, QuickNavi, and Alere BinaxNOW kits were unchanged. Similar results were obtained based on the number of RNA copies $/ \mathrm{mL}$. Although the detection limits were higher than it of influenza A (H1N1) pdm09 virus (Table 1), yet the simulated experiment showed that all POCT kits using in this study can test the H7N9 virus in the PBS, nasopharyngeal swab, sputum and BALF solution. Furthermore, we used the realistic clinical respiratory specimens (URS and LRS) to assess it. The results showed the H7N9 virus of URS and LRS respiratory specimens can be tested positive by RT-PCR methods (Table 2), and the virus copies was higher in the specimens form LRS than those from URS. However, the RNA copies level of these respiratory specimens were lower than the detected limited of these six POCT kits. What ${ }^{\mathbb{S}_{\mathrm{S}}}$ more, the detection results of POCT kits were negative for these clinical samples (Table 2).

On one hand, our results and the other research showed that the POCT kits can test H7N9 virus (Table 1) [6,7]. However, the clinical specimens obtained from the H7N9 patients in the second wave of the epidemic in Guangdong province was tested negative via POCT kits in our study (Table 2). It may be due to the clinical specimens were obtained too late after ill onset (Table 2). A statistical analysis found that specimens obtained within 2-4 days after the onset of illness were the most suitable for virus detection by POCT kits $[11,12]$. Additionally, early specimens (isolated $<12 \mathrm{~h}$ after the onset of illness) and late specimens (isolated $>5$ days after the onset of illness) showed more false-negative results when the specimens were analyzed by POCT kits [10]. On the other hand, we found that the POCT kits using in our study can test the H7N9 virus in different specimen solutions, including nasopharyngeal swab, sputum and BALF specimen solutions in the basal simulated experiment (Table 1), although the detection limit was increased for some POCT kits. Additionally, the other research also

\begin{tabular}{|c|c|c|c|c|c|c|c|}
\hline \multirow[t]{2}{*}{ Designation } & & \multicolumn{6}{|c|}{ Limit of detection $\left(\log _{10} \mathrm{TCID}_{50} / \mathrm{mL}[\mathrm{RNA} \text { copies } / \mathrm{mL}]^{\mathrm{a}}\right)$} \\
\hline & & Vondfo(A+B) & Vondfo(H7) & QuickNavi & ImunoAce & BD Directigen & Alere BinaxNOW \\
\hline \multirow{4}{*}{$\begin{array}{c}\text { human-infected avian } \\
\text { influenza A (H7N9) A/ } \\
\text { Guangzhou/8/2013 }\end{array}$} & PBS & $4.5\left[9.99 \times 10^{7}\right]$ & $5\left[1.76 \times 10^{8}\right]$ & $4.5\left[9.99 \times 10^{7}\right]$ & $4.5\left[9.99 \times 10^{7}\right]$ & $4\left[3.49 \times 10^{7}\right]$ & $5\left[1.76 \times 10^{8}\right]$ \\
\hline & BALF & $4.5\left[5.10 \times 10^{7}\right]$ & $5\left[1.67 \times 10^{8}\right]$ & $5\left[1.67 \times 10^{8}\right]$ & $5\left[1.67 \times 10^{8}\right]$ & $4\left[3.84 \times 10^{7}\right]$ & $5.5\left[4.58 \times 10^{8}\right]$ \\
\hline & SS & $4.5\left[2.44 \times 10^{8}\right]$ & $5.5\left[1.11 \times 10^{9}\right]$ & $4.5\left[2.44 \times 10^{8}\right]$ & $5.5\left[1.11 \times 10^{9}\right]$ & $4.5\left[2.44 \times 10^{8}\right]$ & $5\left[5.98 \times 10^{8}\right]$ \\
\hline & NSS & $4.5\left[2.08 \times 10^{8}\right]$ & $5\left[3.47 \times 10^{8}\right]$ & $4.5\left[2.08 \times 10^{8}\right]$ & $4.5\left[2.08 \times 10^{8}\right]$ & $4\left[4.70 \times 10^{7}\right]$ & $5\left[3.47 \times 10^{8}\right]$ \\
\hline \multirow[t]{4}{*}{ Influenza A (H1N1) pdm09 } & PBS & $2.5\left[8.18 \times 10^{5}\right]$ & - & $1.5\left[2.74 \times 10^{5}\right]$ & $2\left[4.79 \times 10^{5}\right]$ & $2\left[4.79 \times 10^{5}\right]$ & $2.5\left[8.18 \times 10^{5}\right]$ \\
\hline & BALF & $2.5\left[4.68 \times 10^{5}\right]$ & - & $2\left[2.60 \times 10^{5}\right]$ & $2\left[2.60 \times 10^{5}\right]$ & $2\left[2.60 \times 10^{5}\right]$ & $3\left[7.08 \times 10^{5}\right]$ \\
\hline & SS & $2.5\left[2.83 \times 10^{5}\right]$ & - & $2\left[1.28 \times 10^{5}\right]$ & $2.5\left[2.83 \times 10^{5}\right]$ & $2.5\left[2.83 \times 10^{5}\right]$ & $3\left[4.72 \times 10^{5}\right]$ \\
\hline & NSS & $2.5\left[4.60 \times 10^{6}\right]$ & - & $1.5\left[5.27 \times 10^{5}\right]$ & $1.5\left[5.27 \times 10^{5}\right]$ & $1.5\left[5.27 \times 10^{5}\right]$ & $2.5\left[4.06 \times 10^{6}\right]$ \\
\hline
\end{tabular}

PBS: Phosphate-Buffered Saline; BALF: Broncho-Alveolar Lavage Fluid; SS: Sputum Solution; NSS: Nasopharyngeal Swab Solution; log ${ }_{10}$ TCID $_{50} / \mathrm{mL}$ RNA copies/mL] ${ }^{\text {a }}$ RNA copies/mL was tested with real-time RT-PCR with standard thermocycling conditions for the H7 gene with real-time PCR kit (Liferiver, Shanghai, China, RR-0309-02), and the $\mathrm{H} 7$ gene sequence reference to Guangdong Provincial Center for Disease Control and Prevention (CDC).

Table 1: Limit of detection of the POCT kits for the different virus diluents in the basal simulated experiment.

\begin{tabular}{|c|c|c|c|c|c|}
\hline Patient & Sample type ${ }^{a}$ & Numbers & Day after illness onset & RT-PCR (RNA copies/mL) & Six POCT kits ${ }^{c}$ \\
\hline \multirow[t]{4}{*}{1} & TS & 1 & 8 & $4.0 \times 10^{1}$ & \multirow[t]{4}{*}{ Negative } \\
\hline & ETA & 7 & $10 \sim 19$ & $3.57 \times 10^{2} \sim 3.55 \times 10^{4}$ & \\
\hline & Sputum & 4 & $11 \sim 16$ & $5.4 \times 10^{1} \sim 5.9 \times 10^{3}$ & \\
\hline & BALF & 5 & $8 \sim 15$ & $6.3 \times 10^{1} \sim 2.8 \times 10^{5}$ & \\
\hline \multirow[t]{5}{*}{2} & TS & 8 & $14 \sim 21$ & $6.1 \times 10^{1} \sim 1.5 \times 10^{3}$ & \multirow[t]{5}{*}{ Negative } \\
\hline & NPS & 2 & $14 \sim 15$ & $5.8 \times 10^{1}$ & \\
\hline & ETA & 5 & $16 \sim 29$ & $1.0 \times 10^{2} \sim 9.0 \times 10^{4}$ & \\
\hline & Sputum & 14 & $14 \sim 31$ & $1.45 \times 10^{3} \sim 2.6 \times 10^{6}$ & \\
\hline & BALF & 3 & $14 \sim 17$ & $4.94 \times 10^{3} \sim 8.3 \times 10^{4}$ & \\
\hline \multirow[t]{2}{*}{3} & TS & 1 & 11 & $1.52 \times 10^{2}$ & \multirow[t]{2}{*}{ Negative } \\
\hline & ETA & 8 & $11 \sim 19$ & $4.28 \times 10^{2} \sim 6.4 \times 10^{5}$ & \\
\hline 4 & ETA & 4 & $8 \sim 11$ & $2.56 \times 10^{3} \sim 8.8 \times 10^{4}$ & Negative \\
\hline \multirow[t]{2}{*}{5} & TS & 7 & $8 \sim 17$ & $9.53 \times 10^{2} \sim 1.57 \times 10^{5}$ & \multirow[t]{2}{*}{ Negative } \\
\hline & ETA & 12 & $7 \sim 18$ & $1.2 \times 10^{2} \sim 1.9 \times 10^{6}$ & \\
\hline
\end{tabular}

Sample typea: NS: Nasopharyngeal Swab; TS: Throat Swab; NPS: Nasopharyngeal Secretion; ETA: Endotracheal Aspirate; BALF: Sputum And Bronchoalveolar Lavage Fluid; RT-PCR (RNA copies/mL) ${ }^{\text {b: }}$ RT-PCR with standard thermocycling conditions for the H7 gene with real-time PCR kit (Liferiver, Shanghai, China, RR-0309-02), and the $\mathrm{H} 7$ gene sequence reference to Guangdong Provincial Center for Disease Control and Prevention (CDC); Six POCT kits $\mathrm{c}$ : Vondfo(A+B) and Vondfo(H7) (Wondfo, Biotech Company, China), QuickNavi (Denka Seiken, Japan), ImunoAce (TAUNS, Japan), BD Directigen (Becton, Dickinson and company, Sparks, USA) and Alere BinaxNOW (Alere, Unites States)

Table 2: Assess the possibility of testing H7N9 virus in upper or lower respiratory specimens of H7N9-infected patients via rapid point-of-care-test kit. 
Citation: Li Z, Li L, Wu S, Li X, Li R, et al. (2016) Assess the Possibility of Screening and Supervising Influenza A (H7N9) Virus-Infected Patients via Rapid Point-of-Care-Test Kit with Upper or Lower Respiratory Specimens. J Pulm Respir Med 6: 371. doi: 10.4172/2161-105X.1000371

Page 3 of 3

showed that the POCT kits can test H7N9 virus in the clinical samples, particularly ETA, positive [13]. What's more, in our results and the previous research, we also found that the H7N9 virus titer was high and replication last longer in LRT samples, such as sputum and BALF (Table 2) [14]. So that, we think that POCT kits can be used to screen and supervise H7N9 virus-infected patients if in the accurate timing. And the LRT samples, special ETA and sputum, seem a good sample option for detecting H7N9 virus via POCT kits, so we need pay more attention to the LRT samples when the new POCT kits were developed.

\section{Acknowledgments}

Thank you Hidekazu Nishimura gives the POCT kits (QuickNavi and ImunoAce) as a gift to us. Thank you Benjamin Armstrong and Puileng Cheng help to modify the manuscript. This work was partly supported by the Municipal Science and Technology Bureau Foundation of Guangzhou (Grant no.2014Y2-0003), Science and Technology Planning Project of Guangdong Province (Grant no.2013B020224006 \& 2016A050503047).

\section{Refferences}

1. Chen $Y$, Liang $W$, Yang S, Wu N, Gao H, et al. (2013) Human infections with the emerging avian influenza A H7N9 virus from wet market poultry: clinical analysis and characterisation of viral genome. Lancet 381: 1916-1925

2. Ip DK, Liao Q, Wu P, Gao Z, Cao B, et al. (2013) Detection of mild to moderate influenza A/H7N9 infection by China's national sentinel surveillance system for influenza-like illness: case series. BMJ 346: $\mathbf{3 6 9 3}$

3. Lu J, Wu J, Zeng X, Guan D, Zou L, et al. (2014) Continuing reassortment leads to the genetic diversity of influenza virus H7N9 in Guangdong, China. J Virol 88: 8297-8306

4. Lv H, Han J, Zhang P, Lu Y, Wen D, et al. (2013) Mild illness in avian influenza A(H7N9) virus-infected poultry worker, Huzhou, China, April 2013. Emerg Infect Dis 19: $1885-1888$

5. Baas C, Barr IG, Fouchier RA, Kelso A, Hurt AC (2013) A comparison of rapid point-of-care tests for the detection of avian influenza $A(H 7 N 9)$ virus, 2013. Euro Surveill 18

6. Gao R, Cao B, Hu Y, Feng Z, Wang D, et al. (2013) Human infection with a novel avian-origin influenza A (H7N9) virus. N Engl J Med 368: 1888-1897.

7. Chan KH, To KK, Chan JF, Li CP, Chen H, et al. (2013) Analytical sensitivity of seven point-of-care influenza virus detection tests and two molecular tests for detection of avian origin $\mathrm{H} 7 \mathrm{~N} 9$ and swine origin H3N2 variant influenza A viruses. J Clin Microbiol 51: 3160-3161.

8. Guan W, Tsui SK, Lee SM, Yang Z, Luo Y, et al. (2014) Oseltamivir resistance among pandemic $\mathrm{A}(\mathrm{H} 1 \mathrm{~N} 1) 2009$ viruses between 2009 and 2011 in Guangzhou. Zhonghua Jie He He Hu Xi Za Zhi 37: 16-20.

9. Chan KH, Lai ST, Poon LL, Guan Y, Yuen KY, et al. (2009) Analytical sensitivity of rapid influenza antigen detection tests for swine-origin influenza virus (H1N1). J Clin Virol 45: 205-207.

10. Lambert SB, Whiley DM, O'Neill NT, Andrews EC, Canavan FM, et al. (2008) Comparing nose-throat swabs and nasopharyngeal aspirates collected from children with symptoms for respiratory virus identification using real-time polymerase chain reaction. Pediatrics 122: e615-e620.

11. Harper SA Bradley JS, Englund JA, File TM, Gravenstein S, et al. (2009) Seasonal influenza in adults and children--diagnosis, treatment, chemoprophylaxis, and institutional outbreak management: clinical practice guidelines of the Infectious Diseases Society of America. Clin Infect Dis 48: 1003-1032.

12. Landry ML (2011) Diagnostic tests for influenza infection. Curr Opin Pediatr 23: 91-97.

13. Chan KH, To KK, Chan JF, Li CP, Chan KM, et al. (2014) Assessment of antigen and molecular tests with serial specimens from a patient with influenza $A(H 7 N 9)$ infection. J Clin Microbiol 52: 2272-2274.

14. Yang ZF, Mok CK, Liu XQ, Li XB, He JF, et al. (2015) Clinical, virological and immunological features from patients infected with re-emergent avian-origin human H7N9 influenza disease of varying severity in Guangdong province. PLoS One 10: e0117846. 